EPJ Web of Conferences 110,01018 (2016)

DOI: $10.1051 /$ epjconf/201611001018

CC Owned by the authors, published by EDP Sciences, 2016

\title{
SPREADING MODES ON COPPER AND STEEL SURFACES
}

\author{
Dmitry Feoktistov ${ }^{1,2}$, Evgeniya Orlova ${ }^{2, a}$, Anastasiya Islamova ${ }^{2}$ \\ ${ }^{1}$ S. S. Kutateladze Institute of Thermal Physics, Siberian Branch, Russian Academy of Sciences, 630090, \\ Novosibirsk, Russia \\ ${ }^{2}$ National Research Tomsk Polytechnic University, 634050, Tomsk, Russia
}

\begin{abstract}
This work presents the experimental results of the studying the effect of surface roughness, microstructure and liquid flow rate on the dynamic contact angle during spreading of distilled nondeaerated water drop on a solid horizontal substrate. Copper and steel substrates with different roughness have been investigated. Three spreading modes were conventionally indicated. It was found that the spreading of drops on substrates made of different materials occurs in similar modes. However, the duration of each mode for substrates made of copper and steel are different. Spreading of a liquid above the asperities of a surface micro relief was observed to be dominant for large volumetric flow rates of drops $(0.01 \mathrm{ml} / \mathrm{s})$. Liquid was spreading inside the grooves of a rough substrate at low rates $(0.005 \mathrm{ml} / \mathrm{s})$.
\end{abstract}

\section{Introduction}

If a rough surface is wetted, a contact angle is declined from its equilibrium state [1-3]. To characterize this process, the term "effective contact angle" [1] is introduced.

There happen to be two cases of spreading: homogeneous (liquid contacts with the entire surface of the solid body) and heterogeneous (liquid contacts with the surface through the air located in the cavities of the surface) [1]. During homogeneous spreading a high roughness value increases the contact angle on a hydrophobic surface and reduces on a hydrophilic one. It was confirmed experimentally [4] at falling liquid drops on a substrate. Besides, homogeneous spreading is typical for high-velocities of collision, heterogeneous - for low velocities.

The results of experimental studies of nondeaerated distilled water drop spreading on copper and steel substrates are presented in this work.

\section{Experimental procedure}

The experimental investigations were conducted on the setup presented in Fig.1. The experimental method is described in detail in [5].

\footnotetext{
${ }^{a}$ Corresponding author: lafleur@tpu.ru
} 


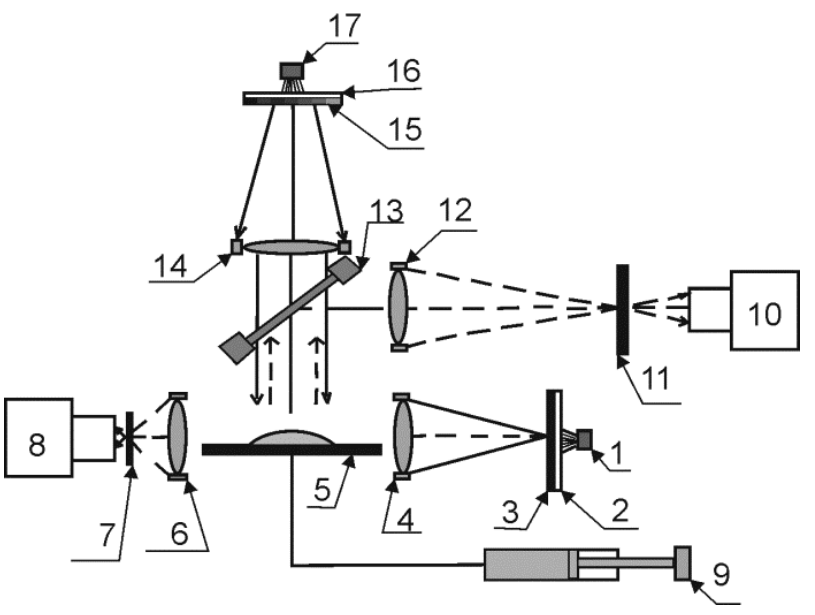

Figure 1. Schematic of an experimental setup: 1, 17 - light source; 2, 16- ground glass; 3, 7, 11 - transparent shield with an opening; 4, 14 - collimating lens; 5- substrate; 6 - condensing lens; 9 - syringe pump; 8,10 high-speed video camera; 12 - Schlieren lens; 13 - beam splitter; 15 - coding filter.

The drop spreading on the surface was implemented by the syringe pump, providing a constant flow rate.

Dynamic contact angle (DCA) and three-phase contact line speed during drop spreading were defined from drop profiles obtained in the experiment. The substrates are the disks $(54 \mathrm{~mm}$ in diameter and $4 \mathrm{~mm}$ in thickness) made of stainless steel and copper with a centered through opening 1 $\mathrm{mm}$ in diameter for liquid squeezing.

A mean surface roughness ( $\mathrm{Ra}$ ) and values of influencing factors were defined (Table 1).

Table 1. The main influencing factors.

\begin{tabular}{|c|c|}
\hline Parameter & Value \\
\hline Wetting liquid & Nondeaerated distilled water \\
\hline Drop volume, $\mathrm{ml}$ & 0.3 \\
\hline Volumetric flow rate of liquid, $\mathrm{ml} / \mathrm{s}$ & $0.005 ; 0.01 ; 0.02 ; 0.04 ; 0.08 ; 0.16$ \\
\hline Material of substrates & copper, stainless steel \\
\hline & stainless steel No1 -1.500 \\
A mean surface roughness Ra, $\mu \mathrm{m}$ & stainless steel No $2-1.554$ \\
& stainless steel No $3-4.590$ \\
& flexible copper No $1-0.591$ \\
& copper No -5.190 \\
& copper No -6.210 \\
\hline
\end{tabular}

The surfaces of substrates were investigated by scanning electron microscope TM-3000 to define a shape and location of micro asperities and cavities. It was found that microstructure of the stainless steel substrate №1 and flexible copper №1 are formed by longitudinally arranged grooves, all others by chaotically arranged asperities and cavities.

\section{Results and discussion}

Time dependences of DCA and three-phase contact line speed on substrates made of copper and stainless steel are presented in Fig. 2 and 3 for low flow rate $(0.005 \mathrm{ml} / \mathrm{s})$. According to results of experimental series spreading modes of water drops were detected for copper substrates (flexible copper №1, copper №2, and copper №3) and stainless steel № 1 .

The following modes were conventionally detected. The first mode is a drop formation, which is characterized by an abrupt increase of DCA and three-phase contact line speed. The second one is 
spreading of a drop; it is accompanied with a monotonic decrease of DCA and three-phase contact line speed. In the final mode when the contact line speed and the driving force tend to zero, an equilibrium contact angle is formed. All described modes are poorly identified on the surfaces of steel №2 and 3.

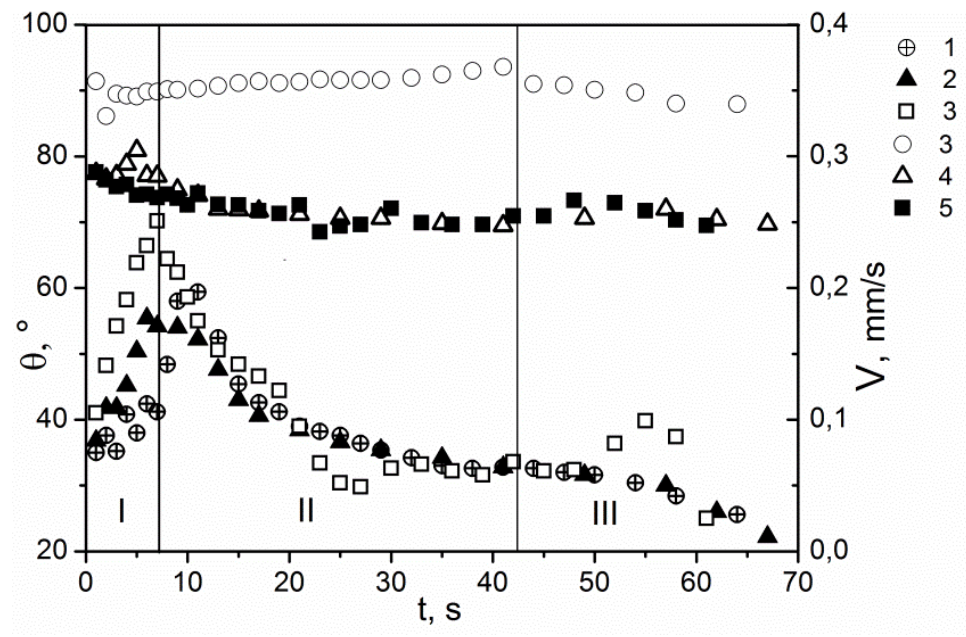

Figure 2. DCA and three-phase contact line speed versus time at liquid flow rate of $0.005 \mathrm{ml} / \mathrm{s}$ on substrates made of copper. Three-phase contact line speed on substrates: 1 - flexible copper No $1 ; 2$ - copper No $2 ; 3$ copper No 3. Advancing DCA: 4 - flexible copper No 1; 5 - copper No 2;6-copper No 3. The numbers are identified spreading modes.

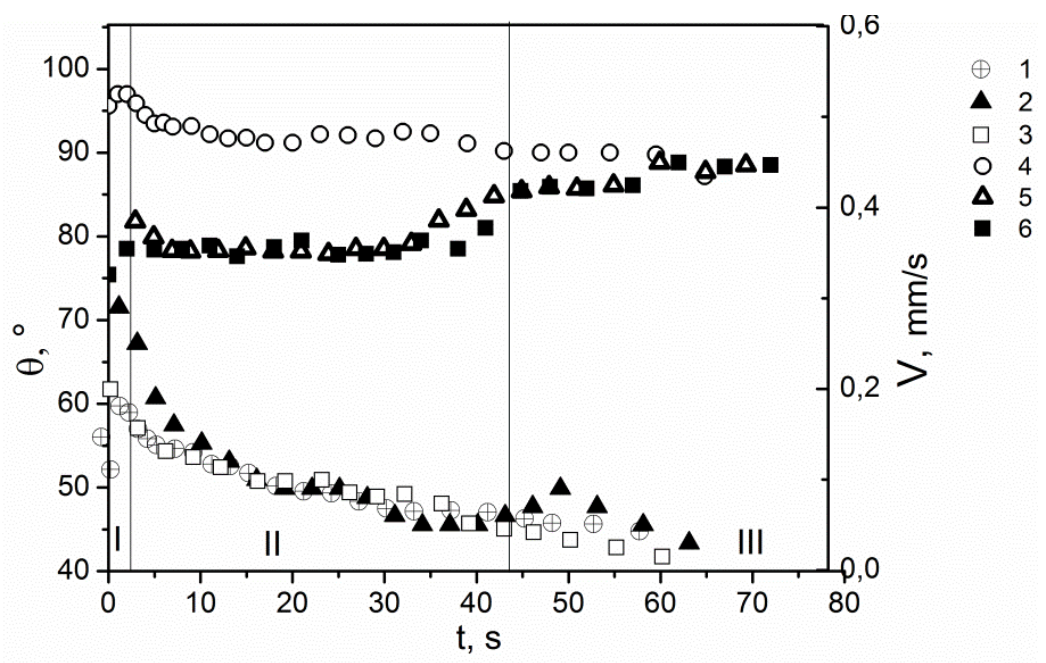

Figure 3. DCA and three-phase contact line speed versus time at liquid flow rate of $0.005 \mathrm{ml} / \mathrm{s}$ on substrates made of stainless steel. Three-phase contact line speed on substrates: 1 - stainless steel No $1 ; 2$ - stainless steel No 2; 3 - stainless steel No 3. Advancing DCA: 4 - stainless steel No 1; 5 - stainless steel No 2;6 - stainless steel No 3. The numbers are identified spreading modes.

It was found that DCA decreases in the second mode of spreading at low liquid flow rate $(0.005$ $\mathrm{ml} / \mathrm{s}, 0.01 \mathrm{ml} / \mathrm{s}$ ) on the surface of stainless steel No 1 . Contact angle increases on the steels No 2 and 3 at volume flow rate of $0.005 \mathrm{ml} / \mathrm{s}$, but it decreases, when flow rate equals to $0.01 \mathrm{ml} / \mathrm{s}$. The reason for this change of angle is the difference in the mean surface roughness. Three-phase contact line is braked by the micro asperities on the rougher surfaces $(\mathrm{Ra}=1.89 \mu \mathrm{m} ; 4.59 \mu \mathrm{m})$; it prevents its movement leading to increase in contact angle. DCA was found to decrease during spreading on rough 
copper substrates in the second mode. However, a slight increase in the angle was observed on the surface of flexible copper No 1. Probably, this phenomenon is connected with the location of spreading front while moving of the contact line towards to surface grooves of the flexible copper.

It was found that the spreading of drops on substrates of different materials occurs in similar modes. However, the duration of each mode for substrates made of copper and steel are different (Table 2).

Table 2. Duration of spreading modes.

\begin{tabular}{|c|c|c|c|}
\hline Material of substrates & Duration of I mode & Duration of II mode & Duration of III mode \\
\hline Copper & $7 \mathrm{~s}$ & $35 \mathrm{~s}$ & $28 \mathrm{~s}$ \\
\hline Stainless steel & $2 \mathrm{~s}$ & $41 \mathrm{~s}$ & $31 \mathrm{~s}$ \\
\hline
\end{tabular}

While investigating the spreading of a drop formed on the surface by the syringe pump (liquid supply from the bottom of a substrate), it was found that spreading of a liquid above the micro asperities on the surface is the dominant for large volumetric flow rates (above $0.01 \mathrm{ml} / \mathrm{s}$ ). Cavities of surface microstructure filled with the air, and the contact between liquid and substrate is a heterogeneous interfacial boundary. And this liquid drop was moving on "air cushion", but not on a solid substrate, that is confirmed by the authors [6]. Low values of rates were characterized by spreading of liquid inside the grooves of a rough substrate. Cavities of surface microstructure filled with the liquid, and the interfacial boundary was the "solid substrate-liquid".

The work was held within the research state assignment "Science" №13.1339.2014/K (Code of Federal Target Scientific and Technical Program 2.1410.2014).

\section{References}

1. L.B. Boinovich, A.M. Emelianenko, Russian Chemical Reviews, 77, 583 (2008)

2. S.Y. Misyura, V.E. Nakoryakov, S.L. Elistratov, Int. J. Heat Mass Transfer, 55, 6609 (2012)

3. O.A. Kabov, D.V. Zaitsev, Doklady Akademii Nauk, 451, 37 (2013)

4. B.J. Stapelbroek, H.P. Jansen, J.H Snoeijer, A. Eddi, Soft matter, 10, 2641 (2014)

5. E.G. Orlova, G. V. Kuznetsov, D. V. Feoktistov, EPJ Web of Conferences, 82, 01053 (2015)

6. T.D. Blake, K.J. Ruschak, Wetting: Static and Dynamic Contact Lines. In: Liquid Film Coating (Chapman \&Hall, London, 1997) 